\title{
Dairy Consumption and Cardiometabolic Diseases: Systematic Review and Updated Meta-Analyses of Prospective Cohort Studies
}

\author{
Sabita S. Soedamah-Muthu ${ }^{1,2} \cdot$ Janette de Goede $^{3}$
}

Published online: 8 November 2018

(C) The Author(s) 2018

\begin{abstract}
Purpose of Review Dairy products contain both beneficial and harmful nutrients in relation to cardiometabolic diseases. Here, we provide the latest scientific evidence regarding the relationship between dairy products and cardiometabolic diseases by reviewing the literature and updating meta-analyses of observational studies.

Recent Findings We updated our previous meta-analyses of cohort studies on type 2 diabetes, coronary heart disease (CHD), and stroke with nine studies and confirmed previous results. Total dairy and low-fat dairy (per $200 \mathrm{~g} / \mathrm{d}$ ) were inversely associated with a 3-4\% lower risk of diabetes. Yogurt was non-linearly inversely associated with diabetes (RR $=0.86,95 \% \mathrm{CI}: 0.83-0.90$ at $80 \mathrm{~g} /$ d). Total dairy and milk were not associated with $\mathrm{CHD}(\mathrm{RR} \sim 1.0)$. An increment of $200 \mathrm{~g}$ of daily milk intake was associated with an $8 \%$ lower risk of stroke.

Summary The latest scientific evidence confirmed neutral or beneficial associations between dairy products and risk of cardiometabolic diseases.
\end{abstract}

Keywords Dairy products · Cardiometabolic $\cdot$ Type 2 diabetes $\cdot$ Coronary heart disease $\cdot$ Stroke

$\begin{array}{ll}\text { Abbreviations } \\ \text { BMI } & \text { Body mass index } \\ \text { CHD } & \text { Coronary heart disease } \\ \text { CI } & \text { Confidence interval } \\ \text { GLST } & \text { Generalized least-square trend } \\ \text { MFGM } & \text { Milk fat globule membranes } \\ \text { RCT } & \text { Randomized controlled trial } \\ \text { RR } & \text { Relative risk } \\ \text { SFA } & \text { Saturated fatty acids }\end{array}$

This article is part of the Topical Collection on Cardiovascular Disease

Electronic supplementary material The online version of this article (https://doi.org/10.1007/s13668-018-0253-y) contains supplementary material, which is available to authorized users.

Sabita S. Soedamah-Muthu

S.S.Soedamah@uvt.nl

1 Center of Research on Psychology in Somatic Diseases (CORPS), Department of Medical and Clinical Psychology, Tilburg University, PO Box 90153, 5000 LE Tilburg, The Netherlands

2 Institute for Food, Nutrition and Health, University of Reading, Reading RG6 6AR, UK

3 Division of Human Nutrition, Wageningen University, Wageningen, The Netherlands

\section{Introduction}

Diet-related cardiometabolic diseases such as type 2 diabetes mellitus, coronary heart disease (CHD), and stroke result in a large global health burden, accounting for over 17 million deaths in 2010 [1•]. Recent data from 195 countries showed that dietary factors have become very important risk factors contributing to worldwide deaths $[2 \cdot, 3]$. It is imperative that the clinical and scientific community identifies modifiable factors that can help to prevent or mitigate these cardiometabolic diseases. Specific foods and overall dietary patterns, rather than single isolated nutrients, are most relevant for chronic disease [4].

Dairy products are worldwide increasingly consumed as indicated by recent tabulations by the International Dairy Federation. From 2006 to 2013, global steep increases in per capita dairy product consumption were found. Especially, Asia, Africa, and Latin America are growing markets for dairy consumption (Fig. 1) [5].

The potential role for dairy products as part of a healthy diet was recognized by several guidelines of Western as well as Asian countries [6-9]. For example, in the US, three daily servings of dairy, mainly low-fat or fat-free, are recommended [7]. In the Netherlands, based on the 2015 food based dietary guidelines [10], daily portions of low-fat and sugar-free milk, 


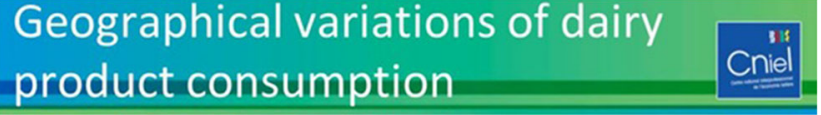

Apparent per capita consumption ( $\mathrm{kg}$ - in milk equivalent)

\begin{tabular}{lccc} 
& 2006 & 2012 & $\%$ \\
\hline World & 101 & 108 & +7 \\
\hline Asia & 61 & 71 & +16 \\
\hline Africa & 42 & 48 & +14 \\
\hline Latin America & 129 & 151 & +17 \\
\hline Russia + Ukraine + Belarus & 253 & 255 & +1 \\
\hline $\begin{array}{l}\text { EU + North America + Australia } \\
\text { + New Zealand }\end{array}$ & 290 & 284 & -2
\end{tabular}

Fig. 1 Per capita Milk Consumption from 2006 to 2012. (Available at https://slideplayer.com/slide/11662620/). From CNIEL/IDF, FAO Food Outlook, PRB [5], with kind permission

yogurt, and cheese are recommended to fit in a balanced healthy diet [11]. The Chinese and Japanese recommendations are $300 \mathrm{ml}$ of daily dairy [8] and two daily servings of milk and dairy products, respectively [9].

Dairy products such as milk, cheese, and yogurt are nutrient-dense as described in Table 1 for the main nutrient contents in these products according to the Dutch Food Composition Tables (www.rivm.nl/nevo). Of note, full-fat milk, still contains considerably less fat than low-fat cheese per $100 \mathrm{~g}$ product. Cheese contains $50 \%$ less water than milk and is therefore more nutrient dense than milk or yogurt. Cheese is relatively high in saturated fat, with low-fat cheese containing $8 \mathrm{~g}$ more fat than low-fat milk or yogurt per $100 \mathrm{~g}$ product. Dairy contains not only various nutrients beneficial for cardiometabolic health such as calcium, potassium, phosphorus, different vitamins such as B2, B12, D and K2, but also harmful nutrients such as sodium, saturated fat, and added sugars [12]. Vitamin D levels of dairy vary between countries depending on fortification. There has been a controversy in the literature over whether dairy products have a prominent role in healthy diets, with alternating more or less focus on beneficial or harmful nutrients [13-15].

Besides high nutrient and energy densities, dairy is heterogeneous comprising many products. For example, butter is a type of dairy, yet it is often grouped with fats and oils because of the role butter has in the diet. Initially in scientific research milk and total dairy, including a variety of products, were grouped together and as such compared between studies [16-18]. In different studies, various definitions of total dairy were used, including differences in (amounts of) combined products, which makes comparisons on associations of dairy with chronic disease complex. A recent shift was made over the past 5 years, with research focusing on teasing out different dairy products by type (milk, cheese, yogurt), fermentation and fat-content (low- and full-fat dairy and milk).

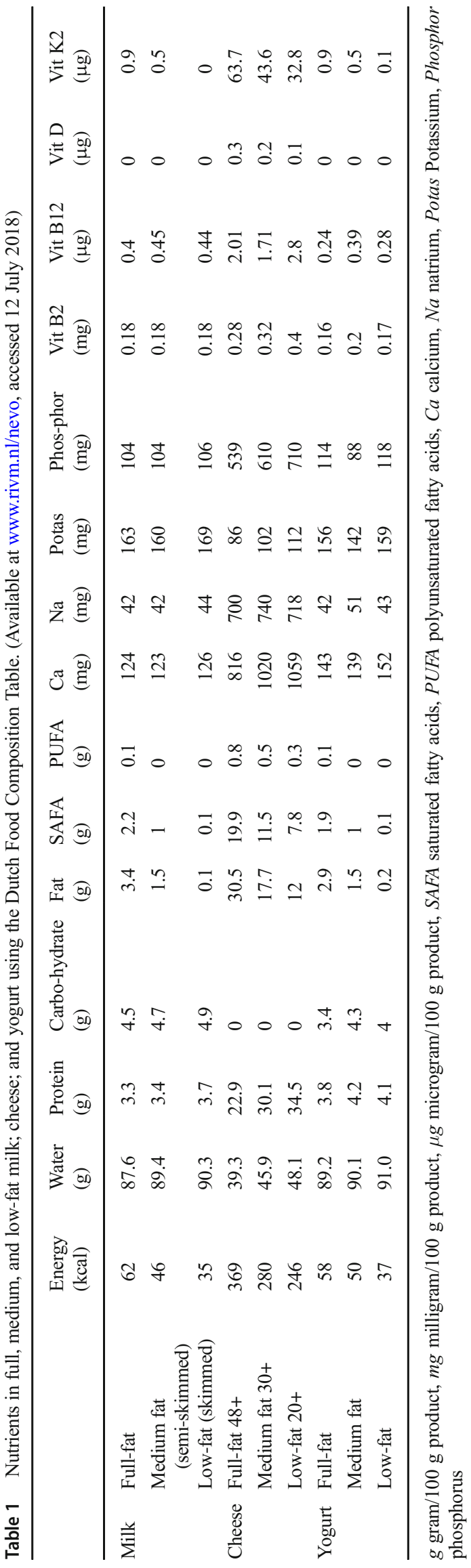


Many reviews and meta-analyses summarizing associations between dairy products and cardiometabolic diseases were published in the past 20 years $[17-20,21 \bullet, 22,23 \bullet$, $24 \bullet \bullet, 25 \bullet \bullet$. Dairy products as specific foods have received increased attention, with controversies and confusion about whether or not to consume more dairy products or more specific dairy products, such as cheese, yogurt, or milk [23••, $24 \bullet \bullet, 25 \bullet \cdot, 26,27]$.

This review provides the latest scientific evidence on dairy products in relation to cardiometabolic diseases (type 2 diabetes, CHD, and stroke). In addition to reviewing a large range of meta-analyses of prospective cohort studies, we identified recent cohort studies to update our previous meta-analyses on dairy in relation to type 2 diabetes, CHD, and stroke [23••, $24 \bullet \bullet, 25 \bullet \cdot$.

\section{Methods}

\section{Literature Search and Selection}

Search syntaxes were similar to our previous meta-analyses $[23 \bullet \bullet, 24 \bullet \bullet, 25 \bullet \cdot$. Published articles, without language restrictions, up to July 2018 were retrieved from PubMed complemented by hand searches of reference lists of recent reviews and meta-analyses. Eligible studies were selected using predefined criteria, i.e., prospective design and reported data on dairy consumption in relation to type 2 diabetes, CHD, and stroke. We excluded studies on animals, children aged < 18 years, and patient populations. Our previous meta-analyses were updated with nine studies [28-36]. The publication of Talaei 2017-II [36] was used to update the CHD results. The previous stroke meta-analysis already contained the (unpublished) data of that study.

\section{Data Extraction}

We extracted descriptive study data as well as ranges of intake, medians or midpoints, numbers of subjects and stroke events, person-years at risk, and relative risks (RRs) with the corresponding 95\% CIs for each category of dairy intake. Portion sizes of dairy products to convert these into grams per day, were generally reported in the included studies. If dairy intake was only reported in servings, without the actual portion size, we used portion sizes of $177 \mathrm{~g}$ for total, low-fat, and full-fat dairy; $244 \mathrm{~g}$ for total, low-fat and full-fat milk; $244 \mathrm{~g}$ for yogurt; and $43 \mathrm{~g}$ for cheese to estimate grams per day. These were mainly UK- [37] and US- [38] based portion sizes for dairy products. For open-ended upper limits of intake, we applied the same width as the adjacent category, whereas for open-ended lowest categories a zero was assigned.

\section{Statistical Analysis}

We performed meta-analyses for type 2 diabetes on total dairy, low-fat dairy, and yogurt, for CHD on total dairy and milk, and for stroke on total dairy, milk, full- and low-fat dairy, for which the most interesting findings were reported in our previously published meta-analyses [23••, 24••, 25••]. Analyses for cheese intake and risk of stroke were not updated due to lack of new studies. If studies presented several statistical models, we included the model that included most confounders. Linearity of associations was investigated using spline analysis and dose-response meta-regression (Generalized Least-Square Trend; GLST). Splined variables were created using MKSPLINE in STATA in order to select the most appropriate knot points of nonlinear associations based on goodness-of-fit tests and Chi-square statistics. Linear and nonlinear associations were further analyzed using dose-response (GLST) meta-regression analysis. Randomeffects meta-regression trend estimation of summarized dose-response data [39] was used to derive the incremental dose-response RRs. Forest plots were created for linear dose-response slopes per $200 \mathrm{~g} / \mathrm{d}$ for total, low-fat, and fullfat dairy and total milk. The shape of the associations within individual studies was visualized by means of Ding's spaghetti plots, as described previously [40]. Between-study heterogeneity was assessed by the Cochrane Q test with an $\mathrm{I}^{2}$ statistic [41]. Statistical analyses were performed using STATA version 11.0 (StataCorp, College Station, TX, USA).

\section{Results}

An overview of all recent reviews and meta-analyses, and prospective cohort studies is summarized in Supplementary Table 1. In the following sections, these reviews and updated meta-analyses are presented for type 2 diabetes, CHD, and stroke.

\section{Dairy and Diabetes, Evidence from Prospective Cohort Studies}

The evidence on the association between dairy products and type 2 diabetes from meta-analyses was summarized recently by Drouin-Chartier et al. [42••] and $\mathrm{Yu}$ and $\mathrm{Hu}$ [43••]. DrouinChartier et al. [42••] summarized meta-analyses (including our work) reporting associations between various dairy products and type 2 diabetes (Fig. 2). Our work [23.•] was rated as reasonably high quality (73\%) compared to the other metaanalyses, according to the Meta-analysis of Observational Study in Epidemiology checklist based on the Grading of Recommendations Assessment, Development, and Evaluation scale. Comparable meta-analyses on dairy products and incident diabetes published prior to ours were from 


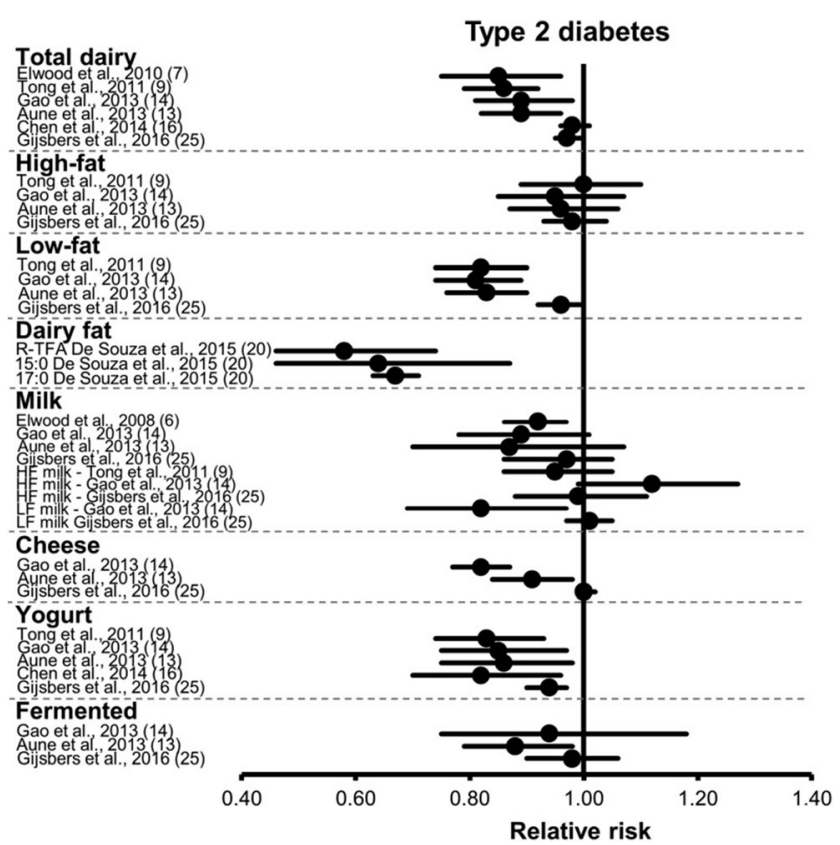

Fig. 2 Summary of meta-analyses on dairy products and risk of type 2 diabetes by Drouin-Chartier [42••]. From Drouin-Chartier JP, Brassard D, Tessier-Grenier M, Cote JA, Labonte ME, Desroches S, et al. Systematic Review of the Association between Dairy Product Consumption and Risk of Cardiovascular-Related Clinical Outcomes. Adv Nutr. 2016;7 [6]:1026-40, by permission of Oxford University Press

Aune et al. [44], Gao et al. [45], Tong et al. [18], Elwood et al. [17], and Chen et al. [46]. The results from all meta-analyses showed consistently neutral or inverse associations for total and low-fat dairy products, with the most striking inverse association for yogurt and type 2 diabetes. Associations for full-fat dairy, milk, and fermented dairy were consistently neutral. The results for cheese, however, differed between the meta-analyses, with an inverse association in the metaanalyses by Aune et al. [44] and Gao et al. [45], but not by Gijsbers et al. [23••], which was the most complete metaanalysis.

The meta-analysis by Aune et al. [44] included eight cheese-specific studies and the final pooled result was driven mostly by the large EPIC-Interact study [47], whereas the meta-analyses by Gijsbers [23••] included 12 cheese-specific studies (13 population samples), including large cohorts like the Nurses' Health Study I and II, the Health Professionals Follow-up Study, the Swedish Malmo Diet and Cancer study. Gao et al. [45] did not show detailed analyses for cheese in a figure and also included fewer cohort studies.

As indicated above, dairy has been the focus in a large number of reviews and meta-analyses. Each one included a different perspective on the topic, with different numbers of studies included. Gijsbers et al. [23••] included 22 cohort studies. In a recent systematic review and meta-analysis by Schwingshackl et al. [48], 21 cohort studies on dairy intake with 44,474 type 2 diabetes cases were included, with a different selection and number of studies when compared to the meta-analysis by Gijsbers et al. Schwingshackl et al. [48] included two studies $[28,49]$, which were not included in Gijsbers et al., because one study [28] was published after the publication by Gijsbers et al. [23••], and one was a crosssectional study [49]. Schwingshackl et al. [48] published more recently than our work, omitted for unknown reasons some prospective cohort studies which were included by Gijsbers et al. [50-52]. Similar inverse associations were reported by Schwingshackl et al. compared with Gijsbers et al. for total dairy. Each additional daily intake of $200 \mathrm{~g}$ of dairy products was inversely associated with diabetes risk (RR: 0.97; $95 \%$ Confidence Interval (CI) $0.94-0.99, \mathrm{I}^{2}=74 \%, n=21$ studies). In subgroup analyses, the inverse association with total dairy and diabetes was observed only in Asian and Australian studies $(\mathrm{RR}=0.84,95 \% \mathrm{CI}$ 0.71-1.01), but not for American and European studies ( $\mathrm{RR}=0.98,95 \%$ CI $0.95-1.01)$. This was also observed by Gijsbers et al. [23••]. Moreover, significant associations were observed by Schwingshackl et al. [48] for studies with $<1000$ type 2 diabetes cases, participants $\geq$ 50 years of age, and a shorter follow-up ( $<10$ years). In subgroup analyses, low-fat dairy products showed a borderline inverse association, whereas no association could be observed for full-fat dairy products [48]. In another recent meta-analysis by Tian et al. [53], a smaller number of studies (11 cohort studies) was summarized for total dairy, full-fat milk, and yogurt results (high vs low dose), with inverse associations of 0.89 (95\% CI $0.84-0.94), 0.87$ (95\%CI: $0.78-0.96$ ), and 0.83 (95\%CI: 0.70-0.98), respectively. These results seemed inflated compared to other meta-analyses, especially for full-fat milk, but several cohort studies were missing $[46,54,55]$ and duplicate results were used [56, 57].

\section{Updated Meta-Analyses on Dairy and Diabetes}

Our previous work (Gijsbers et al.) was the most complete meta-analysis so far, and included 22 prospective cohort studies comprising 579,832 individuals and 43,118 type 2 diabetes cases $[23 \bullet \bullet]$. In summary, we found that total dairy was significantly linearly associated with a $3 \%$ lower risk of diabetes per $200 \mathrm{~g} / \mathrm{d}$, low-fat dairy was borderline significantly associated with a $4 \%$ lower risk per $200 \mathrm{~g} / \mathrm{d}$, and yogurt had the most striking result with a non-linear inverse significant association with diabetes (up to $15 \%$ lower risk). No associations with full-fat dairy, fermented dairy, milk, and cheese were found. In all meta-analyses by Gijsbers et al., considerable significant unexplained heterogeneity was present $\left(I^{2}=66 \%\right.$ for total dairy, $68 \%$ for low-fat dairy, $73 \%$ for yogurt, all $p$ values $<0.05$ ). In subgroup analyses, we found a stronger inverse association for total dairy and total milk consumption in Asian populations (13-15\% lower risk, although not statistically significant), compared to a null association in European populations. This may have 
been due to confounding adjustments (less extensive in the Asian cohorts than in the European cohorts). We updated our meta-analyses for type 2 diabetes with four cohort studies $[28-30,58]$ for the major findings in Gijsbers et al. $[23 \bullet \cdot]$ and similar results were found (Table 2). In total, 26 cohort studies were included. Total dairy (per $200 \mathrm{~g} / \mathrm{d}$ ) was borderline significantly associated with a $3 \%$ lower risk of diabetes, and low-fat dairy was also borderline significantly associated with a $4 \%$ lower risk of diabetes $\left(I^{2}=\right.$ $60 \%$ ) (Supplementary Fig. 1 forest plot low-fat dairy). Yogurt had the most striking result, with a non-linear inverse significant association with diabetes $(\mathrm{RR}=0.86$, $95 \%$ CI $0.83-0.90, p<0.001, I^{2}=69 \%$, at $80 \mathrm{~g} / \mathrm{d}$ compared with $0 \mathrm{~g} / \mathrm{d}$ ) (Fig. 3 Ding's spline plot yogurt). In all these meta-analyses, considerable heterogeneity was present.

\section{Dairy and Coronary Heart Disease, Evidence from Prospective Cohort Studies}

In recent years, several meta-analyses or reviews of metaanalyses have published results on dairy intake or specific

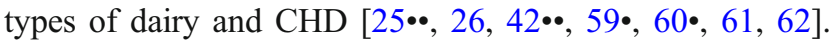

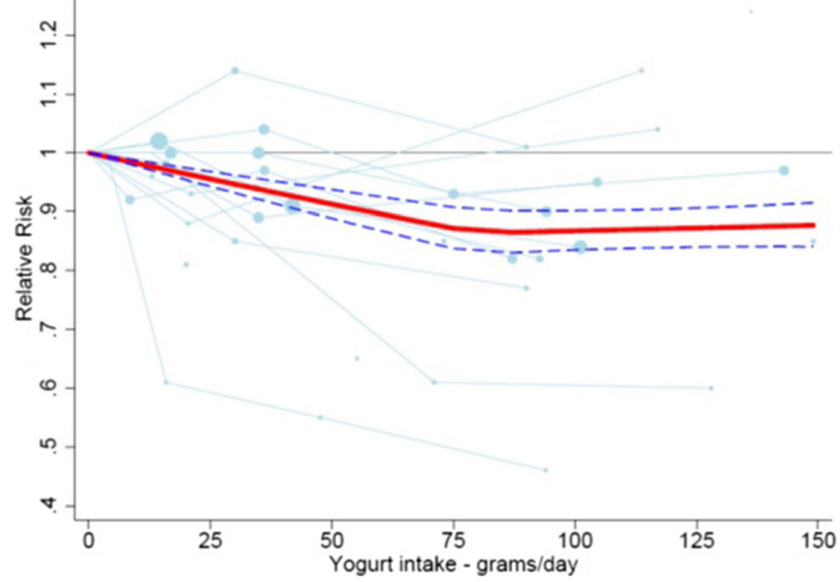

Fig. 3 Ding's Spaghetti plot for yogurt intake and risk of type 2 diabetes

Drouin-Chartier et al. (2016) summarized meta-analyses reporting associations between dairy products and CHD $[42 \bullet \cdot]$. They concluded that, based on moderate to highquality evidence, total dairy, full-fat dairy, low-fat dairy, milk, cheese, and yogurt consumption showed no association with the risk of CHD. Our later meta-analysis by Guo et al. [25••]

Table 2 New results from dose-response meta-analyses (linear and non-linear) on relationships between dairy products, type 2 diabetes, coronary heart disease, and stroke

\begin{tabular}{|c|c|c|c|c|c|c|}
\hline Dairy type (increment g/d) & New studies & $\begin{array}{l}N \text { studies } \\
\text { (samples) }\end{array}$ & RR $(95 \% \mathrm{CI})$ & $\begin{array}{l}\text { Heterogeneity } \\
I^{2}(\%), P\end{array}$ & $\mathrm{~N}$ events; total $\mathrm{N}$ & $\begin{array}{l}\text { Knot, } P \text { nonlinearity } \\
\text { RR }(95 \% \mathrm{CI}) \text { at knot }\end{array}$ \\
\hline \multicolumn{7}{|l|}{ Diabetes mellitus } \\
\hline Total dairy (200) & $\begin{array}{l}\text { Hruby } 2017 \text { [29], } \\
\text { Brouwer-Brolsma } \\
2016 \text { [28], Talaei } 2018 \text { [31], } \\
\text { Virtanen } 2017 \text { [30] }\end{array}$ & $20(21)$ & $0.97(0.95-1.00)$ & $62.8, p<0.001$ & $\begin{array}{l}\text { 46,905; } \\
\quad 5,741,718\end{array}$ & Linear \\
\hline Low-fat dairy (200) & $\begin{array}{l}\text { Hruby } 2017[29] \\
\text { Brouwer-Brolsma } \\
2016[28]\end{array}$ & $15(16)$ & $0.96(0.92-1.00)$ & $60.3, p<0.001$ & $\begin{array}{l}28,531 ; \\
5,313,782\end{array}$ & Linear \\
\hline Yogurt (100) & $\begin{array}{l}\text { Hruby } 2017 \text { [29], } \\
\text { Brouwer-Brolsma } \\
2016[28]\end{array}$ & $13(14)$ & $0.94(0.91-0.97)$ & $68.6, p<0.001$ & $\begin{array}{l}37,223 ; \\
5,184,590\end{array}$ & $\begin{array}{l}\text { Non-linear } 80 \mathrm{~g} / \text { day } \\
\quad p<0.0001,0.86 \\
(0.83-0.90)\end{array}$ \\
\hline \multicolumn{7}{|l|}{ CHD } \\
\hline Total dairy (200) & $\begin{array}{l}\text { Buckland } 2009 \text { [34], } \\
\quad \text { Dilis } 2012 \text { [35], } \\
\text { Talaei Singapore } 2017 \text { [36] }\end{array}$ & $14(16)$ & $1.00(0.98-1.03)$ & $40.2,0.049$ & $\begin{array}{r}11,445 ; \\
3,216,346\end{array}$ & Linear \\
\hline Milk (200) & Talaei Iran 2017 [33] & $12(13)$ & $1.01(0.97-1.04)$ & $40.9,0.061$ & $\begin{array}{l}9176 ; \\
2,231,651\end{array}$ & Linear \\
\hline \multicolumn{7}{|l|}{ Stroke } \\
\hline Total dairy (200) & Haring 2015 [32] & 10 & $0.98(0.96-1.01)$ & $65.6,0.002$ & $\begin{array}{l}11,647 ; \\
2,725,832\end{array}$ & Linear \\
\hline Low-fat dairy (200) & Haring 2015 [32] & $7(9)$ & $0.97(0.95-0.99)$ & $0.0, p=0.68$ & $\begin{array}{l}11,092 ; \\
4,097,631\end{array}$ & $\begin{array}{l}\text { Non-linear } 75 \mathrm{~g} / \text { day, } \\
\quad p=0.007) \\
0.94(0.89-1.002)\end{array}$ \\
\hline Full-fat dairy (200) & Haring 2015 [32] & $6(7)$ & $0.96(0.93-0.99)$ & $0.0, p=0.90$ & $\begin{array}{l}\text { 10,038; } \\
4,076,849\end{array}$ & $\begin{array}{l}\text { Non-linear } 55 \mathrm{~g} / \text { day, } \\
\quad p=0.03 \\
0.96(0.90-1.01)\end{array}$ \\
\hline Milk (200) & Talaei Iran 2017 [33] & $15(17)$ & $0.92(0.88-0.97)$ & $85.2, p<0.001$ & $\begin{array}{l}25,377 ; \\
4,381,604\end{array}$ & $\begin{array}{l}125 \mathrm{~g} / \mathrm{day}, p<0.0001 \\
0.86(0.83-0.89)\end{array}$ \\
\hline
\end{tabular}


was in line with those results, as well as with the meta-analysis by Bechthold et al. [59॰]. Drouin-Chartier noted that associations between fermented dairy and CHD remain uncertain

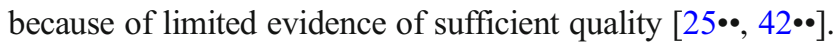
In 2017, Gille et al. [60•] concluded that there is moderate evidence for an inverse association with CHD with the consumption of cheese based on three meta-analyses [26, 61, 62]. Guo et al. [25••] observed a moderate inverse association between fermented dairy and CVD and all-cause mortality, but not with CHD. Another recent meta-analysis with a focus only on total dairy [59•] confirmed neutral associations with CHD.

\section{Updated Meta-Analyses on Dairy and CHD}

We updated our previous meta-analyses for total dairy and milk in relation to CHD [25••] with four cohort studies. In total, 15 cohort studies were included. Total dairy was not associated with incident CHD (Table 2). The results for milk also remained unchanged with RRs (95\% CI) per $200 \mathrm{~g} /$ day of $1.01(0.96-1.06)$ in our previous publication [25.0] and 1.01 (95\% CI $0.97-1.04)$ in the updated meta-analysis (Supplementary Fig. 2).

\section{Dairy and Stroke, Evidence from Prospective Cohort Studies}

In recent years, several meta-analyses or reviews of metaanalyses have published results on dairy intake or specific types of dairy and incident stroke $[24 \bullet \bullet, 26,42 \bullet \bullet, 43 \bullet, 59 \bullet$, $61,63 \cdot \bullet]$. In 2011, we observed a non-significant inverse association of milk with stroke risk with a RR of 0.87 (95\% CI: $0.72-1.07)$ per $200 \mathrm{ml}$ of daily intake in a meta-analysis based on six cohort studies with large heterogeneity [21•]. In a later meta-analysis by $\mathrm{Hu}$ et al. of dairy consumption and stroke risk, the pooled RR was 0.91 (95\% CI 0.82-1.01) for high vs. low milk intake with large heterogeneity, based on nine studies. The association was nonlinear [64].

In 2016, we pooled 18 prospective cohort studies from 11 countries with 8 to 26 years of follow-up that included 762,414 individuals and almost 30,000 stroke events based on a search up to October 2015 [24*•]. An increment of $200 \mathrm{~g}$ of daily milk intake was associated with a $7 \%$ lower risk of stroke (RR $=0.93 ; 95 \%$ CI $0.88-0.98 ; P=0.004 ; I^{2}=$ $86 \%)$. RRs were 0.82 (95\% CI 0.75-0.90) in East Asian and 0.98 (95\% CI $0.95-1.01)$ in Western countries (median intakes 38 and $266 \mathrm{~g} /$ day, respectively) with less but still considerable heterogeneity within the continents. Cheese intake was marginally inversely associated with stroke risk $(\mathrm{RR}=$ 0.97; 95\% CI 0.94-1.01 per 40 g/day). Risk reductions were maximal around $125 \mathrm{~g} /$ day for milk and from $25 \mathrm{~g} /$ day onwards for cheese. Based on a limited number of studies, fullfat milk ( $n=4$ studies) was directly associated with increased stroke risk, whereas full-fat total dairy $(n=6)$, as well as lowfat dairy $(n=7)$ was inversely associated.

The meta-analysis by Chen et al. [26], focused on cheese and no other dairy subtypes in relation to CVD, CHD, and stroke. The meta-analysis included studies until December 2015 and data largely overlapped with our meta-analysis with some minor differences: one Dutch study was missing [65] and for one other Dutch study [66] other results were used [67]. The summary RR for an increment of $40 \mathrm{~g} / \mathrm{d}$ of cheese consumption was 0.94 (95\% CI 0.84-1.04) for stroke risk $\left(I^{2}=64 \%\right)$. The largest risk reduction was observed at approximately $40 \mathrm{~g} / \mathrm{d}$. This non-linear association was also observed in our meta-analysis [24.•], although in our analyses the risk reduction was maximal from $25 \mathrm{~g}$ per day of cheese onwards.

Drouin-Chartier et al. (2016) summarized meta-analyses (not including ours) on various dairy products and stroke $[42 \cdot \bullet]$. Three meta-analyses $[61,62,64]$ concluded that total dairy was inversely associated with stroke, whereas we reported (nine studies) neutral associations [24••], which were confirmed by the most recent meta-analysis including 12 cohort studies by Bechthold et al. [59 $]$ (RR per $200 \mathrm{~g} / \mathrm{d}$ total dairy: $\left.0.98,0.96-1.00 ; I^{2}: 50 \% ; n=11\right)$.

In line with our findings [24••], Drouin-Chartier et al. also found that milk and cheese were associated with a lower risk of stroke in several meta-analyses, with variations in quality of the meta-analyses $[42 \cdot \bullet]$.

$\mathrm{Yu}$ and $\mathrm{Hu}[43 \cdot \bullet$ ] presented in 2018 summaries of recent meta-analyses on dairy and dairy fat intake and cardiometabolic diseases confirming our findings on associations between dairy, cheese, milk, and yogurt with stroke incidence.

\section{New Cohort Studies}

Since our previous meta-analysis [24••], new studies have been published [32, 33, 36, 67]. We updated our previous finding by adding two new cohorts [32,33], one with data for total, lowfat, and full-fat dairy [32] and one with data on full-fat milk [33]. Results of Praagman et al. [67] were (partly) overlapping with already included data of Dalmeijer et al. [66], which we therefore retained. The results from Talaei 2017 based on the Singapore Chinese Health Study [36] had already been included as unpublished results in our meta-analysis. Because those data were based on adjustments as requested by our group, we retained those results. For all four exposures, the results remained largely unchanged (Table 2). An increment of $200 \mathrm{~g}$ of daily milk intake was associated with an $8 \%$ lower risk of stroke (RR: $0.92 ; 95 \%$ CI $0.88-0.97 ; I^{2}=85 \%$ ). RRs were 0.82 (95\% CI 0.75-0.89) in East Asian and 0.98 (95\% CI 0.95-1.01) in Western countries (median intakes 38 and $266 \mathrm{~g} /$ day, respectively) (Fig. 4). Risk reductions were maximal around $125 \mathrm{~g} /$ day for milk (Supplementary Fig. 3). All milk results were similar to our previous findings $[24 \cdot \bullet]$. In the new studies, no 
new data on cheese was presented, so these results were as presented previously.

\section{Conclusion and Discussion}

Scientific evidence from prospective cohort studies to date has suggested null or (weak) inverse associations between dairy intake and risk of type 2 diabetes, CHD, and stroke. This review, adding nine new cohort studies to existing meta-analyses, further confirmed these associations. These results should be placed in the context of observed and unexplained heterogeneity. We presented robust findings in line with pre-

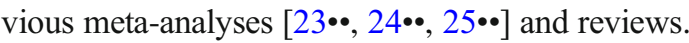

Some differences between meta-analyses [23••, 44, 45] were reported though, even when the analyses covered the same time period of publications. These differences could be caused by different approaches (dose-response analyses versus comparing high vs. low intakes), by the categorization of studies in the various dairy type categories, or by whether or not specific studies were omitted.
Just before finalizing this review, the PURE cohort investigators published dairy data in relation to 9-year incident all-cause mortality, major CVD events, and (fatal and non-fatal) stroke in 21 countries from five continents (136,384 individuals) [68]. This international perspective is an important contribution to the field. Overall, dairy consumption was associated with a lower risk of mortality and major cardiovascular events, especially stroke, but no association was found with myocardial infarction. Milk and yogurt intake were inversely associated with allcause mortality and major CVD events; results for milk in relation to stroke were not provided. Diabetes was not included as an outcome. Associations were consistent for regions with either low or high dairy intakes. The (strong) inverse associations of total dairy with all-cause, CVD, and stroke of the PURE study were not observed in our previ-

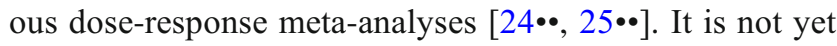
clear which types of dairy were driving the associations of the PURE study. The PURE study was still underpowered to examine the effects of specific dairy types within each region for the various outcomes, but the follow-up and population are still being expanded.

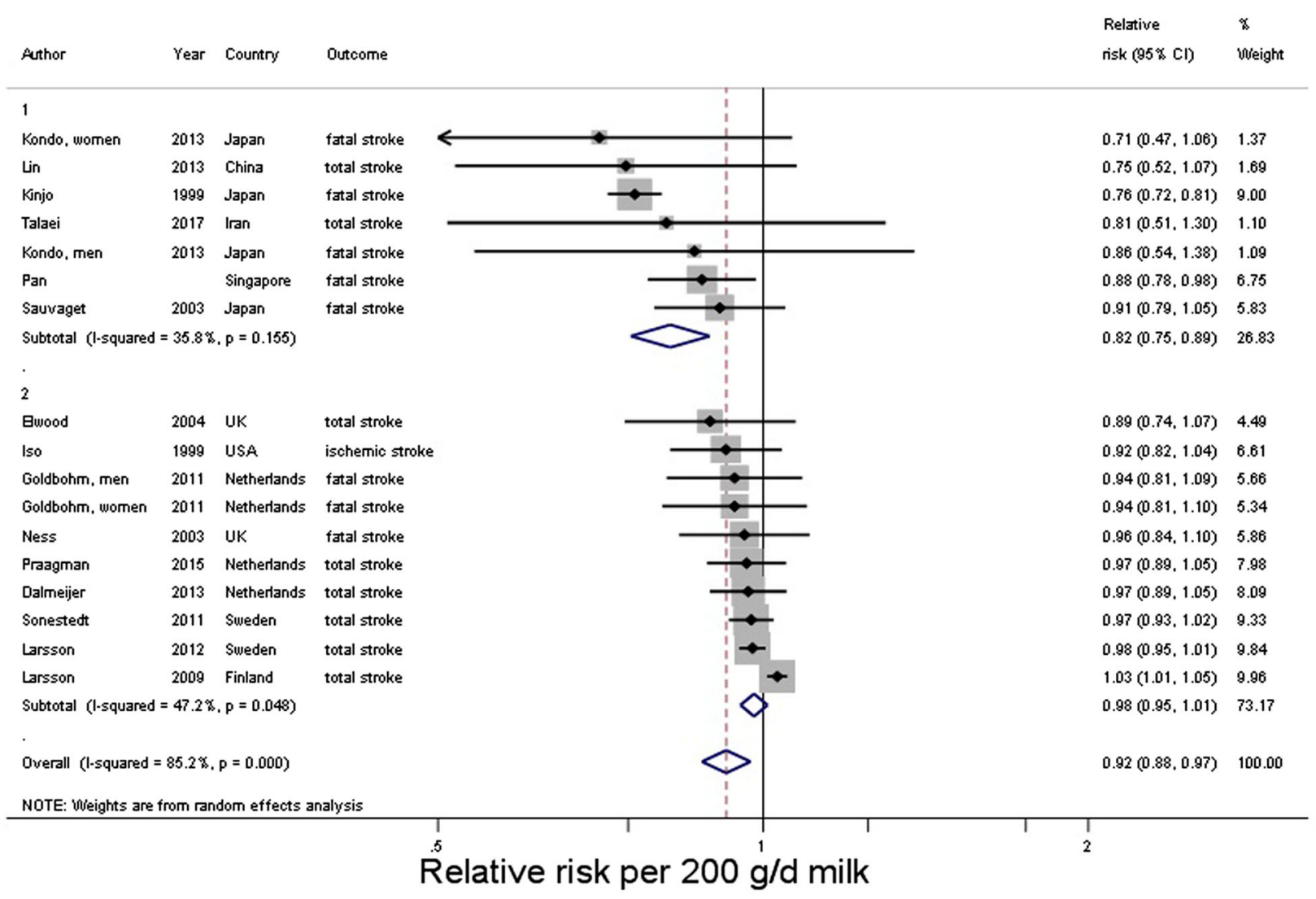

Fig. 4 Forest plot for milk intake and risk of stroke, stratified by continent 
We and others described potential mechanisms previously [23••, 24••]. Regarding the association between yogurt and diabetes, probiotic bacteria, which have been reported to lower blood cholesterol, or potential effects on microbiota $[69,70]$ could possibly play a role. With respect to the association between milk and stroke, minerals such as calcium and potassium have been previously shown to lower blood pressure [71, 72]. Differential effects for full and low-fat yogurt or milk could not be detected.

The current discussions and confusion on health effects of fatty acids have contributed to a shift of thinking from a nutrient-based approach towards a food-based approach. Dietary guidelines traditionally mainly focused on saturated fat in dairy products and its low-density lipoprotein raising effects [6]. However, the link between food sources of saturated fat and CHD is more complicated because food sources of saturated fat contain an array of saturated and unsaturated fatty acids, each of which may differentially affect lipoprotein metabolism, as well as contribute significant amounts of other nutrients, which may alter CHD risk. Recent evidence showed more beneficial associations with cardiometabolic disease for saturated fatty acids (SFA) from dairy products than SFA from meat $[73 \bullet \bullet, 74]$. Furthermore, the food matrix may be important. A meta-analysis of randomized clinical trials (RCTs) studying the effect of cheese consumption on blood lipids and lipoproteins found that cheese caused lower total cholesterol, low-density lipoprotein cholesterol, and high-density lipoprotein cholesterol concentrations compared with butter, despite a similar SFA/polyunsaturated fatty acid ratio [75•].

Butter is the most SFA dense food (50\% SFA). It does not contain milk fat globule membranes (MFGM), as opposed to other types of dairy. A recent RCT showed that, in contrast to milk fat without MFGM, milk fat enclosed by MFGM does not impair the lipoprotein profile [76]. A systematic review and meta-analysis by Pimpin et al. (2016) focused specifically on butter and cardiometabolic diseases [63••]. Based on four studies including 11 country-specific cohorts mainly from Europe with more than 200,000 participants and $\sim 24,000$ incident diabetes cases, butter was inversely associated with type 2 diabetes (RR: 0.96 ; $95 \%$ CI: $0.93-0.99$ per daily $14-\mathrm{g}$ serving). Butter was not associated with CHD or stroke. However, a recent observational study in 71,410 women, aged 50-79 years, showed that substituting butter with tub margarine (teaspoon/day) was associated with a borderline lower risk of myocardial infarction $(\mathrm{HR}=0.95 ; 95 \%$ CI $0.89-1.00$ ) after a follow-up of 13 years [77], which is consistent with what has been found for fatty acid substitution analyses [78]. The potential protective association of tub margarine may be explained by its lower proportion of SFA, trans fatty acids, and higher proportion of monounsaturated fatty acids and polyunsaturated fatty acids, compared with butter.

All evidence of dairy in relation to disease endpoints has been derived from observational studies, and residual confounding remains an issue in this type of research. There is evidence that milk and yogurt intake is related to healthy behaviors [79] and further evidence on causality is warranted. Also, the impact of dairy products per se on health cannot be fully dissociated from that of the foods it replaces $[79,80]$. This needs to be investigated further in the future.

To study causality, additional evidence from RCTs and other types of designs such as Mendelian randomization studies are needed. Drouin-Chartier et al. carried out a comprehensive narrative review on the effects of dairy foods, irrespective of fat content, on cardiometabolic risk factors [81••]. That review included a range of RCTs as well as the metaanalyses of RCTs published by Benatar et al. [82] and De Goede et al. [75•], and the systematic reviews of Turner et al. [83] and Labonté et al. [84]. This paper [81••] was also cited by Gille et al. [60•] in a very recent review on fermented foods and cardiometabolic disease. RCTs, comparing high vs. low dairy or dairy vs. other foods, suggested neutral or no effects of dairy consumption on cardiometabolic risk factors, including insulin resistance, lipids, blood pressure, inflammation, and vascular function [81••]. Currently, there are no RCTs with dairy products as the main intervention with long enough follow-up periods so that cardiometabolic disease endpoints can be studied. Therefore, we are mostly relying on data from observational studies in dietary guidelines around the world. Results of short-term RCTs with effects on cardiovascular risk factors were largely consistent with large prospective cohort studies assessing associations between dairy products and cardiometabolic diseases as summarized in this review. Ideally, well-designed RCTs with longterm interventions are needed to confirm these effects on cardiometabolic disease endpoints. The design of the control group in future RCTs on dairy foods needs to be chosen carefully to ensure that foods consumed in replacement of dairy reflect consumers' choices and dietary habits. As described by Drouin-Chartier et al. [81••] various foods used in the RCTs to substitute dairy products in the control low-dairy or dairy-free diets affect the results and interpretation and make direct comparison between RCTs difficult.

Mendelian randomization analyses have been more widely used to assess potential causal estimates of environmental risk factors with health outcomes. This type of analysis has the advantage over observational studies of minimizing confounding by using genetic markers as instrumental variables of environmental risk factors and therefore assessing causality. A recent Mendelian randomization analysis [85•] using 22 observational studies with 197,332 participants examined the causal effect of dairy consumption on systolic blood pressure and risk of hypertension, to confirm previously found inverse relationships between milk and hypertension [86]. There was no association between genetically determined dairy intake and systolic blood pressure or incident hypertension [85•, 87]. Similarly, Mendelian randomization studies found no 
associations between milk and diabetes [88-90] and CHD [90, 91] which is in line with intake-based results for milk in relation to diabetes and CHD. The only associations reported from Mendelian randomization studies were between genetically determined milk intake and higher BMI [92, 93]. Interestingly, no Mendelian randomization study for milk in relation to stroke has yet been performed. Lactase persistence genes used in Mendelian randomization studies characterize lactase containing dairy or milk intake, but not yogurt or cheese. Most prominent results from meta-analyses on dairy and diabetes, are found for yogurt intake and not milk or cheese. To our knowledge, it is not possible for Mendelian randomization studies to separate effects for milk, cheese, and yogurt, highlighting areas for future research.

This systematic review showed neutral or beneficial associations between specific dairy products and risk of type 2 diabetes, CHD, and stroke. In updated meta-analyses, higher milk intake was inversely associated with risk of stroke, but not with risk of CHD or type 2 diabetes. Stronger inverse associations for milk and stroke were found in Asian vs. Western populations, but this has to be investigated further with more Asian population samples. Cheese was not related to diabetes, conflicting with some of the earlier meta-analyses, depending on which studies were included. Most striking results were found for yogurt and type 2 diabetes, but this finding could also be due to more healthy behaviors which are associated with yogurt consumers [79]. Future epidemiological research should focus on more careful consideration of confounding factors, and replacement diets. Distinguishing between full and low-fat cheese and yogurt, or milk and yogurt with or without added sugars is not possible with the current literature. Additional evidence from RCTs and other study designs such as Mendelian Randomization studies should be integrated with conventional epidemiological studies to investigate further mechanisms and causality.

\section{Compliance with Ethical Standards}

Conflict of Interest Sabita S. Soedamah-Muthu received unrestricted grants for prior meta-analyses work by the Dutch Dairy Association, Global Dairy Platform, The Dairy Research Institute and Dairy Australia. She also received the Wiebe Visser International Dairy Nutrition Prize (2014) for her research output on dairy and cardiometabolic diseases.

Janette de Goede declares that she has no conflict of interest.

Human and Animal Rights and Informed Consent This article does not contain any studies with human or animal subjects performed by any of the authors.

Open Access This article is distributed under the terms of the Creative Commons Attribution 4.0 International License (http:// creativecommons.org/licenses/by/4.0/), which permits unrestricted use, distribution, and reproduction in any medium, provided you give appropriate credit to the original author(s) and the source, provide a link to the Creative Commons license, and indicate if changes were made.

\section{References}

Papers of particular interest, published recently, have been highlighted as:

- Of importance

- Of major importance

1. Global Burden of Metabolic Risk Factors for Chronic Diseases Collaboration. Cardiovascular disease, chronic kidney disease, and diabetes mortality burden of cardiometabolic risk factors from 1980 to 2010: a comparative risk assessment. Lancet Diabetes Endocrinol. 2014;2(8):634-47. This study highlights the importance of lowering cardiometabolic risks through dietary, behavioural, and pharmacological interventions as part of the global public health policies.

2. Global Burden of Disease Risk Factors Collaborators. Global, regional, and national comparative risk assessment of 84 behavioural, environmental and occupational, and metabolic risks or clusters of risks, 1990-2016: a systematic analysis for the Global Burden of Disease Study 2016. Lancet. 2017;390(10100):1345-422. The Global Burden of Diseases Collaboration estimated in 2016 that the leading risk factors in terms of attributable disability adjusted life-years (DALYs) worldwide were malnutrition, diet, high blood pressure, smoking, and air pollution. This highlights the importance of diet as contributing factor to health loss.

3. Lim SS, Vos T, Flaxman AD, Danaei G, Shibuya K, Adair-Rohani $\mathrm{H}$, et al. A comparative risk assessment of burden of disease and injury attributable to 67 risk factors and risk factor clusters in 21 regions, 1990-2010: a systematic analysis for the global burden of disease study 2010. Lancet. 2012;380(9859):2224-60.

4. Mozaffarian D, Ludwig DS. Dietary guidelines in the 21 st centurya time for food. JAMA. 2010;304(6):681-2.

5. Centre National Interprofessionnel de l'Economie Laitière (CNIEL)/ International Dairy Federation (IDF), Food and Agriculture Organization (FAO) Food Outlook, PRB. Per capita milk consumption from 2006 to 2012. Annual National Workshop for Dairy Economists and Policy Analysts presented in Boston in May 2013.

6. U.S. Department of Agriculture and U.S. Department of Health and Human Services. Dietary Guidelines for Americans. 7th Edition, Washington, DC: U.S. Government Printing Office; December 2010.

7. USDA. http://www.choosemyplate.gov/food-groups/dairy-amount. html [Jun 1, 2015].

8. Ge K. The transition of Chinese dietary guidelines and food guide pagoda. Asia Pac J Clin Nutr. 2011;20(3):439-46.

9. Japanese food guide spinning top [Jul 1, 2015]. Available from: http://www.mhlw.go.jp/bunya/kenkou/pdf/eiyou-syokuji4.pdf.

10. Kromhout D, Spaaij CJ, de Goede J, Weggemans RM. The 2015 Dutch food-based dietary guidelines. Eur J Clin Nutr. 2016;70(8): 869-78.

11. Brink L, Postma-Smeets A, Stafleu A, Wolvers D. Richtlijnen Schijf van Vijf, Voedingscentrum. Voedingscentrum: Den Haag; 2016.

12. Mozaffarian D, Wu JHY. Flavonoids, dairy foods, and cardiovascular and metabolic health: a review of emerging biologic pathways. Circ Res. 2018;122(2):369-84.

13. van Aerde MA, Soedamah-Muthu SS, Geleijnse JM, Snijder MB, Nijpels G, Stehouwer CD, et al. Dairy intake in relation to cardiovascular disease mortality and all-cause mortality: the Hoorn study. Eur J Nutr. 2013;52(2):609-16.

14. Tognon G, Rothenberg E, Petrolo M, Sundh V, Lissner L. Dairy product intake and mortality in a cohort of 70-year-old Swedes: a 
contribution to the Nordic diet discussion. Eur J Nutr. 2017. https:// doi.org/10.1007/s00394-017-1556-2.

15. Givens DI. Milk and meat in our diet: good or bad for health? Animal. 2010;4(12):1941-52.

16. Pittas AG, Lau J, Hu FB, Dawson-Hughes B. The role of vitamin D and calcium in type 2 diabetes. A systematic review and metaanalysis. J Clin Endocrinol Metab. 2007;92(6):2017-29.

17. Elwood PC, Givens DI, Beswick AD, Fehily AM, Pickering JE, Gallacher J. The survival advantage of milk and dairy consumption: an overview of evidence from cohort studies of vascular diseases, diabetes and cancer. J Am Coll Nutr. 2008;27(6):723s-34s.

18. Tong X, Dong JY, Wu ZW, Li W, Qin LQ. Dairy consumption and risk of type 2 diabetes mellitus: a meta-analysis of cohort studies. Eur J Clin Nutr. 2011;65(9):1027-31.

19. Elwood P. Milk, coronary disease and mortality. J Epidemiol Community Health. 2001;55(6):375.

20. Tremblay A, Gilbert JA. Milk products, insulin resistance syndrome and type 2 diabetes. J Am Coll Nutr. 2009;28(Suppl 1):91S-102S.

21. Soedamah-Muthu SS, Ding EL, Al-Delaimy WK, Hu FB, Engberink MF, Willett WC, et al. Milk and dairy consumption and incidence of cardiovascular diseases and all-cause mortality: dose-response meta-analysis of prospective cohort studies. Am J Clin Nutr. 2011;93(1):158-71. This dose-response meta-analysis of prospective studies in 2011 on dairy products in relation to CVD and all-cause mortality risk, was the first dose-reponse meta-analysis to indicate that milk intake was not associated with all-cause mortality but possibly inversely associated with overall CVD or stroke risk; however, these findings were based on limited numbers and limited dairy products (focus on milk).

22. Kratz M, Baars T, Guyenet S. The relationship between high-fat dairy consumption and obesity, cardiovascular, and metabolic disease. Eur J Nutr. 2013;52(1):1-24.

23.• Gijsbers L, Ding EL, Malik VS, de Goede J, Geleijnse JM, Soedamah-Muthu SS. Consumption of dairy foods and diabetes incidence: a dose-response meta-analysis of observational studies. Am J Clin Nutr. 2016;103(4):1111-24. This dose-response systematic review and meta-analysis indicated a possible role for dairy foods, particularly yogurt, in the prevention of type 2 diabetes.

24.• de Goede J, Soedamah-Muthu SS, Pan A, Gijsbers L, Geleijnse JM. Dairy consumption and risk of stroke: a systematic review and updated dose-response meta-analysis of prospective cohort studies. J Am Heart Assoc. 2016;5(5). https://doi.org/10.1161/JAHA.115. 002787. This systematic review and dose-response meta-analysis of milk and other dairy products in relation to stroke risk showed that milk consumption was inversely associated with stroke risk, especially in Asian countries. Cheese intake was marginally inversely associated with stroke risk.

25.• Guo J, Astrup A, Lovegrove JA, Gijsbers L, Givens DI, SoedamahMuthu SS. Milk and dairy consumption and risk of cardiovascular diseases and all-cause mortality: dose-response meta-analysis of prospective cohort studies. Eur J Epidemiol. 2017;32(4):269-87. This is a systematic review and dose-response meta-analysis of milk and other dairy products in relation to CVD, CHD and allcause mortality. In general neutral or inverse associations were found for dairy products and these outcomes.

26. Chen GC, Wang Y, Tong X, Szeto IMY, Smit G, Li ZN, et al. Cheese consumption and risk of cardiovascular disease: a metaanalysis of prospective studies. Eur J Nutr. 2017;56(8):2565-75.

27. Dinicolantonio JJ, Harcombe Z, O'Keefe JH. Problems with the 2015 dietary guidelines for Americans. An Alternative. Minn Med. 2016;99(6):40-3.

28. Brouwer-Brolsma EM, van Woudenbergh GJ, Oude Elferink SJ, Singh-Povel CM, Hofman A, Dehghan A, et al. Intake of different types of dairy and its prospective association with risk of type 2 diabetes: the Rotterdam study. Nutr Metab Cardiovasc Dis. 2016;26(11):987-95.

29. Hruby A, Ma J, Rogers G, Meigs JB, Jacques PF. Associations of dairy intake with incident prediabetes or diabetes in middle-aged adults vary by both dairy type and glycemic status. J Nutr. 2017;147(9):1764-75.

30. Virtanen HEK, Koskinen TT, Voutilainen S, Mursu J, Tuomainen TP, Kokko P, et al. Intake of different dietary proteins and risk of type 2 diabetes in men: the Kuopio Ischaemic Heart Disease Risk Factor Study. Br J Nutr. 2017;117(6):882-93.

31. Talaei M, Pan A, Yuan JM, Koh WP. Dairy intake and risk of type 2 diabetes. Clin Nutr. 2018;37(2):712-8.

32. Haring B, Misialek JR, Rebholz CM, Petruski-Ivleva N, Gottesman RF, Mosley TH, et al. Association of dietary protein consumption with incident silent cerebral infarcts and stroke: the Atherosclerosis Risk in Communities (ARIC) study. Stroke. 2015;46(12):3443-50.

33. Talaei M, Hosseini N, van Dam RM, Sadeghi M, Oveisgharan S, Dianatkhah M, et al. Whole milk consumption and risk of cardiovascular disease and mortality: Isfahan cohort study. Eur J Nutr. 2017;56(7):2343-52.

34. Buckland G, Gonzalez CA, Agudo A, Vilardell M, Berenguer A, Amiano P, et al. Adherence to the Mediterranean diet and risk of coronary heart disease in the Spanish EPIC cohort study. Am J Epidemiol. 2009;170(12):1518-29.

35. Dilis V, Katsoulis M, Lagiou P, Trichopoulos D, Naska A, Trichopoulou A. Mediterranean diet and CHD: the Greek European prospective investigation into cancer and nutrition cohort. Br J Nutr. 2012;108(4):699-709.

36. Talaei M, Koh WP, Yuan JM, Pan A. The association between dairy product intake and cardiovascular disease mortality in Chinese adults. Eur J Nutr. 2017;56(7):2343-52.

37. Food Standards Agency. Food portion sizes. 3rd ed. Norwich, London: TSO; 2005.

38. Bodner-Montville J, Ahuja JKC, Ingwersen LA, Haggerty ES, Enns CW, Perloff BP. USDA Food and Nutrient Database for dietary studies: released on the web. J Food Compos Anal. 2006;19(SUPPL):S100-S7.

39. Greenland S, Longnecker MP. Methods for trend estimation from summarized dose-response data, with applications to meta-analysis. Am J Epidemiol. 1992;135(11):1301-9.

40. Bauer SR, Hankinson SE, Bertone-Johnson ER, Ding EL. Plasma vitamin D levels, menopause, and risk of breast cancer: doseresponse meta-analysis of prospective studies. Medicine (Baltimore). 2013;92(3):123-31.

41. Higgins JP, Thompson SG. Quantifying heterogeneity in a metaanalysis. Stat Med. 2002;21(11):1539-58.

42.• Drouin-Chartier JP, Brassard D, Tessier-Grenier M, Cote JA, Labonte ME, Desroches S, et al. Systematic review of the association between dairy product consumption and risk of cardiovascular-related clinical outcomes. Adv Nutr. 2016;7(6): 1026-40. This is a systematic review including summaries of earlier published meta-analyses on prospective cohort studies associating dairy consumption with cardiometabolic diseases. The main conclusion was that the consumption of various forms of dairy products showed either favorable or neutral associations with cardiometabolic diseases. Further research was recommended to study effects of full and low-fat dairy on cardiometabolic diseases.

43.• Yu E, Hu FB. Dairy products, dairy fatty acids, and the prevention of cardiometabolic disease: a review of recent evidence. Curr Atheroscler Rep. 2018;20(5):24. This recent review contains summaries of meta-analyses and showed that null or weak inverse associations were shown between consumption of dairy products and risk of cardiovascular disease. Replacing dairy fat with polyunsaturated fatty acids, especially from plant-based foods, may confer further health benefits. 
44. Aune D, Norat T, Romundstad P, Vatten LJ. Dairy products and the risk of type 2 diabetes: a systematic review and dose-response metaanalysis of cohort studies. Am J Clin Nutr. 2013;98(4):1066-83.

45. Gao D, Ning N, Wang C, Wang Y, Li Q, Meng Z, et al. Dairy products consumption and risk of type 2 diabetes: systematic review and dose-response meta-analysis. PLoS One. 2013;8(9): e73965.

46. Chen M, Sun Q, Giovannucci E, Mozaffarian D, Manson JE, Willett WC, et al. Dairy consumption and risk of type 2 diabetes: 3 cohorts of US adults and an updated meta-analysis. BMC Med. 2014;12:215.

47. Sluijs I, Forouhi NG, Beulens JW, van der Schouw YT, Agnoli C, Arriola L, et al. The amount and type of dairy product intake and incident type 2 diabetes: results from the EPIC-InterAct study. Am J Clin Nutr. 2012;96(2):382-90.

48. Schwingshackl L, Hoffmann G, Lampousi AM, Knuppel S, Iqbal $\mathrm{K}$, Schwedhelm C, et al. Food groups and risk of type 2 diabetes mellitus: a systematic review and meta-analysis of prospective studies. Eur J Epidemiol. 2017;32(5):363-75.

49. Moslehi N, Shab-Bidar S, Mirmiran P, Sadeghi M, Azizi F. Associations between dairy products consumption and risk of type 2 diabetes: Tehran lipid and glucose study. Int J Food Sci Nutr. 2015;66(6):692-9.

50. Fuhrman BJ, Smit E, Crespo CJ, Garcia-Palmieri MR. Coffee intake and risk of incident diabetes in Puerto Rican men: results from the Puerto Rico Heart Health Program. Public Health Nutr. 2009;12(6):842-8.

51. Nettleton JA, Steffen LM, Ni H, Liu K, Jacobs DR Jr. Dietary patterns and risk of incident type 2 diabetes in the multi-ethnic study of atherosclerosis (MESA). Diabetes Care. 2008;31(9): 1777-82.

52. O'Connor LM, Lentjes MA, Luben RN, Khaw KT, Wareham NJ, Forouhi NG. Dietary dairy product intake and incident type 2 diabetes: a prospective study using dietary data from a 7-day food diary. Diabetologia. 2014;57(5):909-17.

53. Tian S, Xu Q, Jiang R, Han T, Sun C, Na L. Dietary protein consumption and the risk of type 2 diabetes: a systematic review and meta-analysis of cohort studies. Nutrients. 2017 Sep 6;9(9). https:// doi.org/10.3390/nu9090982.

54. Villegas R, Gao YT, Dai Q, Yang G, Cai H, Li H, et al. Dietary calcium and magnesium intakes and the risk of type 2 diabetes: the Shanghai Women's Health Study. Am J Clin Nutr. 2009;89(4): 1059-67.

55. Ericson U, Hellstrand S, Brunkwall L, Schulz CA, Sonestedt E, Wallstrom P, et al. Food sources of fat may clarify the inconsistent role of dietary fat intake for incidence of type 2 diabetes. Am J Clin Nutr. 2015;101(5):1065-80.

56. Grantham NM, Magliano DJ, Hodge A, Jowett J, Meikle P, Shaw JE. The association between dairy food intake and the incidence of diabetes in Australia: the Australian Diabetes Obesity and Lifestyle Study (AusDiab). Public Health Nutr. 2013;16(2):339-45.

57. Choi HK, Willett WC, Stampfer MJ, Rimm E, Hu FB. Dairy consumption and risk of type 2 diabetes mellitus in men: a prospective study. Arch Intern Med. 2005;165(9):997-1003.

58. Talaei M, Pan A, Yuan JM, Koh WP. Reply to Kawada letter to editor about "dairy intake and risk of type 2 diabetes". Clin Nutr. 2017;36(6): 1738.

59. Bechthold A, Boeing H, Schwedhelm C, Hoffmann G, Knuppel S, Iqbal K, et al. Food groups and risk of coronary heart disease, stroke and heart failure: a systematic review and dose-response meta-analysis of prospective studies. Crit Rev Food Sci Nutr. 2017 Oct 17:120. https://doi.org/10.1080/10408398.2017.1392288. This review of prospective cohort studies comprised 12 main food groups, including dairy foods, in relation to stroke, coronary heart disease and heart failure. Similar null associations for total dairy, full and low-fat dairy were reported as in other reviews and meta-analyses, although specific dairy foods were not analysed.

60. Gille D, Schmid A, Walther B, Vergeres G. Fermented food and non-communicable chronic diseases: a review. Nutrients. $2018 \mathrm{Apr}$ 4;10(4). https://doi.org/10.3390/nu10040448. This review summarised meta-analyses of prospective cohort studies and randomized controlled trials on fermented foods, including fermented dairy, and chronic diseases.

61. Alexander DD, Bylsma LC, Vargas AJ, Cohen SS, Doucette A, Mohamed M, et al. Dairy consumption and CVD: a systematic review and meta-analysis. Br J Nutr. 2016;115(4):737-50.

62. Qin LQ, Xu JY, Han SF, Zhang ZL, Zhao YY, Szeto IM. Dairy consumption and risk of cardiovascular disease: an updated metaanalysis of prospective cohort studies. Asia Pac J Clin Nutr. 2015;24(1):90-100.

63.• Pimpin L, Wu JH, Haskelberg H, Del Gobbo L, Mozaffarian D. Is butter back? A systematic review and meta-analysis of butter consumption and risk of cardiovascular disease, diabetes, and total mortality. PLoS One. 2016;11(6):e0158118. A systematic review and meta-analysis focused specifically on butter. Based on a limited number of studies, butter was inversely associated with diabetes type 2, with no associations for CHD or stroke.

64. Hu D, Huang J, Wang Y, Zhang D, Qu Y. Dairy foods and risk of stroke: a meta-analysis of prospective cohort studies. Nutr Metab Cardiovasc Dis. 2014;24(5):460-9.

65. Praagman J, Franco OH, Ikram MA, Soedamah-Muthu SS, Engberink MF, van Rooij FJ, et al. Dairy products and the risk of stroke and coronary heart disease: the Rotterdam study. Eur J Nutr. 2015;54(6):981-90.

66. Dalmeijer GW, Struijk EA, van der Schouw YT, Soedamah-Muthu SS, Verschuren WM, Boer JM, et al. Dairy intake and coronary heart disease or stroke-a population-based cohort study. Int $\mathrm{J}$ Cardiol. 2013;167(3):925-9.

67. Praagman J, Dalmeijer GW, van der Schouw YT, Soedamah-Muthu SS, Monique Verschuren WM, Bas Bueno-de-Mesquita H, et al. The relationship between fermented food intake and mortality risk in the European prospective investigation into cancer and nutritionNetherlands cohort. Br J Nutr. 2015;113(3):498-506.

68. Dehghan M, Mente A, Rangarajan S, Sheridan P, Mohan V, Iqbal $\mathrm{R}$, et al. Association of dairy intake with cardiovascular disease and mortality in 21 countries from five continents (PURE): a prospective cohort study. Lancet. 2018. https://doi.org/10.1016/S01406736(18)31812-9.

69. Lisko DJ, Johnston GP, Johnston CG. Effects of dietary yogurt on the healthy human gastrointestinal (GI) microbiome. Microorganisms. 2017 Feb 15;5(1). https://doi.org/10.3390/ microorganisms5010006.

70. Parvez S, Malik KA, Ah Kang S, Kim HY. Probiotics and their fermented food products are beneficial for health. J Appl Microbiol. 2006;100(6):1171-85.

71. Geleijnse JM, Kok FJ, Grobbee DE. Blood pressure response to changes in sodium and potassium intake: a metaregression analysis of randomised trials. J Hum Hypertens. 2003;17(7):471-80.

72. van Mierlo LA, Arends LR, Streppel MT, Zeegers MP, Kok FJ, Grobbee DE, et al. Blood pressure response to calcium supplementation: a meta-analysis of randomized controlled trials. J Hum Hypertens. 2006;20(8):571-80.

73.• de Oliveira Otto MC, Mozaffarian D, Kromhout D, Bertoni AG, Sibley CT, Jacobs DR Jr, et al. Dietary intake of saturated fat by food source and incident cardiovascular disease: the multi-ethnic study of atherosclerosis. Am J Clin Nutr. 2012;96(2):397-404. Using the Multi-Ethnic Study of Atherosclerosis cohort study associations of Saturated fatty (SF) intake from different food sources and the incidence of CVD events were investigated. In this prospective cohort study, a higher intake of saturated fat from dairy was associated with lower CVD risk and a higher 
intake of saturated fat from meat with a higher CVD risk. This study contributed to discussions on specific types of saturated fatty acids and the role of the food matrix.

74. Liu S, van der Schouw YT, Soedamah-Muthu SS, Spijkerman AMW, Sluijs I. Intake of dietary saturated fatty acids and risk of type 2 diabetes in the European prospective investigation into Cancer and nutrition-Netherlands cohort: associations by types, sources of fatty acids and substitution by macronutrients. Eur J Nutr. 2018. https://doi.org/10.1007/s00394-018-1630-4.

75. de Goede J, Geleijnse JM, Ding EL, Soedamah-Muthu SS. Effect of cheese consumption on blood lipids: a systematic review and meta-analysis of randomized controlled trials. Nutr Rev. 2015;73(5):259-75. Based on this meta-analysis of 5 randomized controlled trials, cheese intake, compared to butter intake reduced total, low-density lipoprotein cholesterol and highdensity lipoprotein cholesterol, but had no effect on triglycerides, despite similar polyunsaturated/saturated fatty acid ratios in both foods. This study contributed to discussions on the role of the food matrix.

76. Rosqvist F, Smedman A, Lindmark-Mansson H, Paulsson M, Petrus P, Straniero S, et al. Potential role of milk fat globule membrane in modulating plasma lipoproteins, gene expression, and cholesterol metabolism in humans: a randomized study. Am J Clin Nutr. 2015;102(1):20-30.

77. Liu Q, Rossouw JE, Roberts MB, Liu S, Johnson KC, Shikany JM, et al. Theoretical effects of substituting butter with margarine on risk of cardiovascular disease. Epidemiology. 2017;28(1):145-56.

78. Jakobsen MU, O'Reilly EJ, Heitmann BL, Pereira MA, Balter K, Fraser GE, et al. Major types of dietary fat and risk of coronary heart disease: a pooled analysis of 11 cohort studies. Am J Clin Nutr. 2009;89(5):1425-32.

79. Tremblay A, Panahi S. Yogurt consumption as a signature of a healthy diet and lifestyle. J Nutr. 2017;147(7):1476S-80S.

80. Lamarche B, Givens DI, Soedamah-Muthu S, Krauss RM, Jakobsen MU, Bischoff-Ferrari HA, et al. Does milk consumption contribute to cardiometabolic health and overall diet quality? Can J Cardiol. 2016;32(8):1026-32.

81.• Drouin-Chartier JP, Cote JA, Labonte ME, Brassard D, TessierGrenier M, Desroches S, et al. Comprehensive review of the impact of dairy foods and dairy fat on cardiometabolic risk. Adv Nutr. 2016;7(6):1041-51. This narrative review summarizes evidence from RCTs of dairy consumption on cardiometabolic risk factors, including lipids, blood pressure, inflammation, insulin resistance and vascular function. In general, no effects or weak evidence was reported for effects of dairy foods on cardiometabolic risk.

82. Benatar JR, Sidhu K, Stewart RA. Effects of high and low fat dairy food on cardio-metabolic risk factors: a meta-analysis of randomized studies. PLoS One. 2013;8(10):e76480.
83. Turner KM, Keogh JB, Clifton PM. Dairy consumption and insulin sensitivity: a systematic review of short- and long-term intervention studies. Nutr Metab Cardiovasc Dis. 2015;25(1):3-8.

84. Labonte ME, Couture P, Richard C, Desroches S, Lamarche B. Impact of dairy products on biomarkers of inflammation: a systematic review of randomized controlled nutritional intervention studies in overweight and obese adults. Am J Clin Nutr. 2013;97(4): 706-17.

85. Ding M, Huang T, Bergholdt HK, Nordestgaard BG, Ellervik C, Qi L, et al. Dairy consumption, systolic blood pressure, and risk of hypertension: Mendelian randomization study. BMJ. 2017;356: j1000. Using the CHARGE Consortium 22 studies were analysed with Mendelian randomisation methods and a metaanalyses was conducted of an additional eight published RCTs on the association of dairy consumption with systolic blood pressure. Both the Mendelian Randomisation study and metaanalysis of RCTs did not support an association between dairy consumption and systolic blood pressure.

86. Soedamah-Muthu SS, Verberne LD, Ding EL, Engberink MF, Geleijnse JM. Dairy consumption and incidence of hypertension: a dose-response meta-analysis of prospective cohort studies. Hypertension. 2012;60(5):1131-7.

87. Hartwig FP, Horta BL, Smith GD, de Mola CL, Victora CG. Association of lactase persistence genotype with milk consumption, obesity and blood pressure: a Mendelian randomization study in the 1982 Pelotas (Brazil) birth cohort, with a systematic review and meta-analysis. Int J Epidemiol. 2016;45(5):1573-87.

88. Bergholdt HK, Nordestgaard BG, Ellervik C. Milk intake is not associated with low risk of diabetes or overweight-obesity: a Mendelian randomization study in 97,811 Danish individuals. Am J Clin Nutr. 2015;102(2):487-96.

89. Vissers LET, van der Schouw YT, Sluijs I. Challenge in interpretation of Mendelian randomization studies using lactase persistence as instrumental variable. Eur J Clin Nutr. 2018;72(1):179-80.

90. Yang Q, Lin SL, Au Yeung SL, Kwok MK, Xu L, Leung GM, et al. Genetically predicted milk consumption and bone health, ischemic heart disease and type 2 diabetes: a Mendelian randomization study. Eur J Clin Nutr. 2017;71(8):1008-12.

91. Bergholdt HK, Nordestgaard BG, Varbo A, Ellervik C. Milk intake is not associated with ischaemic heart disease in observational or Mendelian randomization analyses in 98,529 Danish adults. Int J Epidemiol. 2015;44(2):587-603.

92. Lamri A, Poli A, Emery N, Bellili N, Velho G, Lantieri O, et al. The lactase persistence genotype is associated with body mass index and dairy consumption in the D.E.S.I.R. study. Metabolism. 2013;62(9):1323-9.

93. Mendelian Randomization of Dairy Consumption Working Group. Dairy consumption and body mass index among adults: Mendelian randomization analysis of 184802 individuals from 25 studies. Clin Chem. 2018;64(1):183-91. 